\title{
Concepções alternativas sobre conceitos básicos de física de estudantes ingressantes em curso superior da área tecnológica: um estudo comparativo
}

\section{Alternative conceptions about basic concepts of physics of ingress students in higher education course of the technological area: a comparative study}

\author{
João Carlos Krause* \\ Neusa Maria John Scheid ${ }^{* *}$
}

\section{Resumo}

Os resultados de pesquisa na área de educação em ciências indicam que as concepções alternativas (CAs), também consideradas concepções intuitivas ou espontâneas, que os estudantes apresentam ao ingressarem em um curso superior são cruciais na aprendizagem dos conceitos básicos de disciplinas da área de ciências naturais. $\mathrm{A}$ premissa é que essas concepções, que os estudantes trazem para a sala de aula, e com as quais explicam boa parte dos fenômenos naturais que os cercam, fazem parte do conhecimento que possuem e que elas influenciam, sobremaneira, a aprendizagem de conceitos - como os de física básica, por exemplo - quando eles ingressam em cursos superiores da área tecnológica. Na presente investigação, buscou-se identificar a presença das CAs em estudantes ingressantes em cursos de engenharia de uma instituição de ensino superior da Região das Missões, no Rio Grande do Sul, em dois períodos, com intervalo de oito anos. A metodologia de abordagem quanti-qualitativa orientou a obtenção de dados por meio de um questionário com questões baseadas no trabalho de Axt (1986), Peduzzi (2005) e Viennot (1979). Os resultados apresentaram uma recorrência ou a manutenção das mesmas CAs em conteúdos de física básica nas duas épocas consideradas. Concluiu-se que, apesar de as investigações sobre as CAs terem sido intensas nas últimas décadas, com propostas bem fundamentadas, o estudo comparativo realizado demonstra que essas, com pequenas variações estatísticas, continuam sendo as mesmas. Diante disso, argumenta-se que, na formação de professores, esses resultados deverão ser considerados, de modo a buscar estratégias metodológicas para a resolução dessas CAs, ainda na educação básica.

Palavras-chave: Conceitos básicos de física. Ensino de física. Formação de professores.

\section{Abstract}

Research results in the area of Education in Sciences indicate that the Alternative Conceptions (CAs), also known as intuitive or spontaneous conceptions, that the students present when joining a higher education course, are crucial in the learning of basic concepts of disciplines in the area of Natural Sciences. The premise is that these conceptions, that the students bring along into the classroom, and with which explain much of natural phenomena that surround them, are part of the knowledge that they possess and influence, in particular, the

Recebido em 28/10/2017 - Aprovado em 13/01/2018

http://dx.doi.org/10.5335/rep.v25i2.8157

Doutor em Física experimental pela Universidade Federal do Rio Grande do Sul. Docente Permanente do Programa de Pós-Graduação em Ensino Científico e Tecnológico e professor de Física na Universidade Regional Integrada do Alto Uruguai e Missões, Santo Ângelo, RS. E-mail: krause@san.uri.br

* Doutora em Educação Científica e Tecnológica pela Universidade Federal de Santa Catarina. Docente Permanente do Programa de Pós-Graduação em Ensino Científico e Tecnológico e professora de Biologia na Universidade Regional Integrada do Alto Uruguai e Missões, Santo Ângelo, RS. E-mail: neusas@san.uri.br 


\begin{abstract}
learning of concepts - such as those of basic Physics, for example - when joining in higher education courses of the technological area. In the present research, it was sought to identify the presence of CAs in ingress students in courses of engineering in a higher education institution in the Missões Region - RS, in two periods, with eight years of interval. The methodology, of quanti-qualitative approach, guided the collection of data using a questionnaire with questions based on the work of Axt (1986), Peduzzi (2005), and Viennot (1979). The results showed a recurrence or maintenance of the same CAs in contents of basic Physics in the two considered periods. It was concluded that, regardless that the investigations about the CAs have been intense in the last decades, with well-supported proposals, the carried out comparative study, proves that these, with small statistical variations, continue to be the same. Therefore, it is argued that, in the formation of teachers, these results should be considered, seeking methodological strategies for the settling of these CAs, still in the basic education.
\end{abstract}

Keywords: Basic concepts of physics. Teaching of physics. Teacher formation.

\title{
Introdução
}

Uma breve busca em uma base de dados por artigos relacionados à área de ensino revela, em diferentes épocas, um bom número de pesquisas com estudos apontando dificuldades da grande maioria dos estudantes no aprendizado de conceitos físicos, seja no ensino básico, seja no superior (AXT, 1986; DRIVER, 1986; GIORDAN; DE VECCHI, 1996; HARRES, 1993; LOUZADA; ELIA; SAMPAIO, 2015; PEDUZZI, 2005; VIENNOT, 1979). Este fato, mais que consolidado na literatura sobre o assunto, passa, muitas vezes, pelas dificuldades dos professores em promover uma aprendizagem significativa dos conceitos, mas também se relaciona com as deficiências advindas de etapas anteriores de ensino, quer seja pela não assimilação dos conceitos quer seja simplesmente pela influência das concepções alternativas (CAs) dos estudantes e desconsideradas, na maioria das vezes, pelos professores. As CAs, consideradas também como concepções intuitivas ou espontâneas, são trazidas pelos alunos para a sala de aula e explicam boa parte dos fenômenos que os cercam, fazendo parte do seu conhecimento. Os estudos que investigam as concepções alternativas em vários conteúdos da Física são consideráveis (AXT, 1986; LOUZADA; ELIA; SAMPAIO, 2015; PEDUZZI, 2005; SILVA; NÚÑEZ, 2007; SILVEIRA, 2013). Algumas dessas pesquisas (HARRES, 1993; SILVA, E., 2004) apresentam aspectos relativos ao diagnóstico das CAs.

De forma geral, as CAs, presentes nas mais diversas áreas, têm sido investigadas de maneira exaustiva, não só aquelas apresentadas por estudantes (CARVALHO; COUTO; BOSSOLAN, 2012; CORREAA et al., 2010; FIGUEIRA; ROCHA, 2011; HARRES, 1993; KÖHNLEIN, 2013; LOUZADA; ELIA; SAMPAIO, 2015; PEDUZZI, 2005), mas também aquelas ainda presentes em professores (KRAUSE; SANTOS; SANDRI, 2012; SILVEIRA, 2013). O professor tem um papel muito importante no processo de ensino e deve ter a capacidade de detectar as CAs e de usá-las de forma que esses erros conceituais façam parte do processo de aprendizagem 
nas diversas áreas de ensino. Considerando o relativo longo tempo em que as CAs são investigadas, observa-se que os resultados desses estudos não são implementados na prática pedagógica, seja pela "distância” entre os pesquisadores e aqueles que devem "ensinar" os conteúdos científicos seja pelas próprias CAs apresentadas pelos professores (KRAUSE; SANTOS; SANDRI, 2012).

Pode-se observar que, embora as investigações sobre o assunto sejam extensas, as pesquisas não têm sido eficientes para mudar o panorama, corroborando a afirmação de Delizoicov, Angotti e Pernambuco (2002) de que, em relação aos objetos de investigação e à qualidade das pesquisas na área do ensino de ciências naturais, a produção brasileira é comparável à dos países mais avançados. A disseminação dos resultados entre os pares é considerada satisfatória, dado o grande número de congressos, de revistas para publicação e de referências mútuas utilizadas. No entanto, o que preocupa são a incipiente apropriação, a reconstrução e o debate sistemático dos resultados de pesquisa na sala de aula e na prática docente que, nos três níveis de ensino, deixa muito a desejar (SCHEID, 2006).

$\mathrm{O}$ escopo da presente pesquisa foi elucidar esses aspectos investigando a presença das CAs em estudantes ingressantes em cursos de engenharia em uma universidade da Região das Missões, RS, e comparando-se as concepções alternativas de física básica apresentadas em dois períodos, com intervalo de oito anos.

\section{As concepções alternativas e a aprendizagem na área de ciências naturais}

Os conhecimentos que os alunos trazem para a sala de aula - as CAs - são construídos por eles desde o seu nascimento e se fazem presentes no seu dia a dia, emergindo na sala de aula, momento em que os conceitos científicos estariam sendo inseridos no processo de ensino e aprendizagem.

Segundo Figueira e Rocha (2011), as CAs são caracterizadas como construções pessoais elaboradas de forma espontânea, por meio da interação dos alunos com o meio ambiente em que vivem e com a troca de conhecimentos com outras pessoas. $\mathrm{O}$ uso das CAs pelos estudantes no ambiente de ensino permite que eles organizem e deem sentido às situações-problemas apresentadas no processo de ensino.

Para Silva e Núñez (2007), as CAs, em geral, são incoerentes com o conhecimento científico, pois nelas estão contidas as bases (ou esquemas mentais) de erros conceituais que os estudantes manifestam quando precisam resolver problemas que exigem o conhecimento científico. 
De acordo com Cavellucci (2010), as características gerais das CAs são:

a) representações subjetivas: as CAs possuem natureza pessoal; cada indivíduo interioriza a sua experiência de um modo próprio, e as CAs são influenciadas, mas não ditadas, por contribuições do meio;

b) natureza estruturada: as CAs são constituídas como uma estrutura organizada de conhecimentos solidários, de simples e isolados para gerais e complexos;

c) dotados de certa coerência interna: as CAs são sentidas pelos alunos como sensatas, coerentes e úteis; considerando seus modelos de pensamento, têm um valor significativo;

d) esquemas mutuamente inconsistentes: os alunos usam diferentes CAs para interpretar situações que exigiriam a mesma explicação e CAs iguais para interpretar situações que exigiriam diferentes explicações;

e) esquemas que fazem lembrar modelos históricos da ciência já ultrapassados: utilizam-se de conceitos já tidos como corretos pela ciência;

f) esquemas resistentes a mudanças e persistentes: as CAs têm um caráter regressivo.

Esta resistência à mudança parece ser também uma das características mais marcantes das CAs, pois indivíduos de diferentes faixas etárias apresentam o mesmo padrão de CAs, independentemente do tempo de instrução tradicional de ciência (SILVA, A., 2004). O amplo poder explicativo das CAs ocorre porque o indivíduo, principalmente, não se preocupa muito com a coerência e com a abrangência dos conceitos e, ao mesmo tempo, apoia-se em uma visão egocêntrica do mundo. Esse comportamento também é frequentemente observado não só em crianças, mas também na adolescência e na fase adulta. $O$ fato é que, para explicar situações inteiramente opostas, muitas vezes, os alunos usam as mesmas explicações, fazendo apenas suas modificações para explicar o fenômeno, mas sem reduzir o nível da sua validade (HARRES, 1993).

Assim, as CAs têm forte influência na aprendizagem dos alunos, o que faz com que eles nem sempre tenham um resultado positivo em sua aprendizagem. Segundo Harres (1993), para que os alunos deixem de lado as CAs, inicialmente, devem experimentar insatisfação com suas ideias e se convencer de que as mudanças parciais em suas explicações não funcionam. De acordo com o autor, a presença dessas inquietações com suas explicações para determinados fenômenos se constitui na principal fonte de insatisfação, que só pode ser experimentada quando fracassa a tentativa de usar os seus conceitos numa nova situação, sem chance de "interpretar" a nova experiência. 
Em resumo, tendo em vista a forte presença das CAs em situações de aprendizagem, fazer com que o indivíduo transforme ou tenha consciência desses aspectos errôneos presentes em seus conceitos tornaria o processo de ensino e aprendizagem mais eficiente. Dessa maneira, como afirma Moreira (2010), haveria um processo que resultaria em uma aprendizagem significativa, isto é,

[...] aquela em que ideias expressas simbolicamente interagem de maneira substantiva $\mathrm{e}$ não arbitrária com aquilo que o aprendiz já sabe. Substantiva quer dizer não literal, não ao pé-da-letra, e não arbitrária significa que a interação não é com qualquer ideia prévia, mas sim com algum conhecimento especificamente relevante já existente na estrutura cognitiva do sujeito que aprende.

A este conhecimento, especificamente relevante à nova aprendizagem, o qual pode ser, por exemplo, um símbolo já significativo, um conceito, uma proposição, um modelo mental, uma imagem, David Ausubel (1918-2008) chamava de subsunçor ou ideia-âncora.

Em termos simples, subsunçor é o nome que se dá a um conhecimento específico, existente na estrutura de conhecimentos do indivíduo, que permite dar significado a um novo conhecimento que lhe é apresentado ou por ele descoberto. Tanto por recepção como por descobrimento, a atribuição de significados a novos conhecimentos depende da existência de conhecimentos prévios especificamente relevantes e da interação com eles (MOREIRA, 2010, p. 02).

Em caso de não ocorrer a interação das novas informações com ideias já ancoradas (subsunçores) existentes, na estrutura cognitiva do indivíduo, a aprendizagem seria apenas automática ou mecânica. Isso fica claro em boa parte dos alunos de nossas escolas, que, quando expostos a determinadas situações-problemas, buscam aplicações de fórmulas prontas sem considerar aspectos conceituais ou apenas respondem corretamente a situações em que a aplicação de equações é eficiente para encontrar a solução.

Considerando o fato de que as CAs poderiam ser consideradas ideias relevantes disponíveis que serviriam de subsunçores, nos quais o novo conhecimento a ser aprendido seria ancorado, poderia se romper com a aprendizagem mecânica. Dessa forma, estar-se-ia considerando o argumento principal do processo de aprendizagem significativa, que se baseia no fato de que novas ideias se relacionam com aquilo que o aprendiz já sabe e que o resultado dessa interação é o surgimento de um novo significado. De acordo com o que estabelecem Ausubel (2003), Moreira e Masini (2006) e Faria (1989), três condições são necessárias para que efetivamente tal aprendizagem ocorra:

a) disponibilidade na estrutura cognitiva de conceitos ou proposições relevantes (ideias âncoras, subsunçores) que possibilitem a interação;

b) disposição, por parte do aprendiz, em relacionar as ideias novas com as ideias existentes, já ancoradas em sua estrutura cognitiva;

c) existência de um material (nova informação) potencialmente significativo. 
Diante desse contexto, as CAs apresentadas pelos estudantes poderiam ser consideradas como os conceitos disponíveis para possibilitar a interação com os novos conhecimentos. E, quando já se tivesse clareza em relação às CAs apresentadas pelos estudantes, seria de extrema importância vislumbrar um processo que possibilitasse a mudança desse quadro.

Assim, as evidências de uma aprendizagem significativa apareceriam com mudanças nos níveis de CAs apresentadas por estudantes já ao concluírem o ensino médio, aspecto que os resultados do presente trabalho deixam claro que não vem ocorrendo na região considerada.

\section{Metodologia}

O presente estudo caracteriza-se como uma pesquisa qualitativa e quantitativa de caráter exploratório e descritivo, realizada com acadêmicos de ambos os gêneros ingressantes em cursos universitários de engenharias de uma instituição de ensino superior da Região das Missões, no estado do Rio Grande do Sul. Considerou-se mais conveniente realizar a pesquisa apenas com alunos ingressantes em cursos relacionados a áreas correlatas a Ciências Exatas, no caso engenharia, pelo fato de que, em princípio, esses sujeitos estariam mais interessados e/ou familiarizados com os assuntos abordados.

A pesquisa teve a aprovação do Comitê de Ética em Pesquisa da Universidade Regional Integrada do Alto Uruguai e das Missões (URI/Santo Ângelo). Os participantes, alunos maiores de 18 anos e pais de alunos menores de idade, de forma voluntária, aceitaram fazer parte desta pesquisa, assinando o termo de consentimento livre e esclarecido. Participaram da pesquisa 218 estudantes entre $17 \mathrm{e}$ 27 anos, sendo 158 no ano de 2008 e 60 no ano de 2016. Os cursos envolvidos, em 2008, foram: Engenharia Civil e Engenharia Mecânica. No ano de 2016, foram considerados os ingressantes em: Engenharia Civil, Engenharia Elétrica, Engenharia Mecânica e Engenharia Química. Embora, em 2016, tenha sido o dobro de cursos de engenharia, houve um menor número de participantes na pesquisa (60), devido ao decréscimo de ingressantes nesses cursos na instituição alvo da pesquisa no período.

O instrumento de pesquisa aplicado foi um questionário anônimo com questões sobre as CAs relativas à área de cinemática, especificamente com relação às concepções sobre força, atrito, aceleração e velocidade. Assim, o questionário foi constituído por cinco questões, baseadas nos trabalhos de Axt (1986), Peduzzi (2005) e Viennot (1979). A resposta da primeira deveria ser: sim ou não; as demais tinham cinco alternativas, das quais quatro se identificavam com alguma CA e 
uma com a concepção científica correta para o tópico considerado. As alternativas foram elaboradas de forma que representassem as respostas mais comuns relatadas no trabalho de investigação de Peduzzi (2005).

As respostas dos questionários foram tabuladas e analisadas em gráficos de modo a obter os resultados sobre as concepções alternativas presentes nos alunos em duas diferentes épocas (2008 e 2016), permitindo, dessa forma, uma análise comparativa. Os resultados da pesquisa e algumas discussões sobre os aspectos mais relevantes obtidos são apresentados a seguir.

\section{Resultados e suas repercussões para o ensino de física}

O instrumento de pesquisa era constituído por cinco questões que versavam sobre conceitos de física básica, mais especificamente sobre força, aceleração, atrito e velocidade, e foi respondido por 218 acadêmicos.

A primeira questão do questionário indagava sobre as forças que estão atuando nas diferentes trajetórias de objetos arremessados para cima (Figura 1), indicando diferentes sentidos para o vetor velocidade em determinado instante. Nesse sentido, o aluno deveria responder se as forças agindo em cada um dos objetos no instante mostrado seriam iguais ou diferentes, desprezando a resistência do ar.

Figura 1 - Primeira questão do questionário

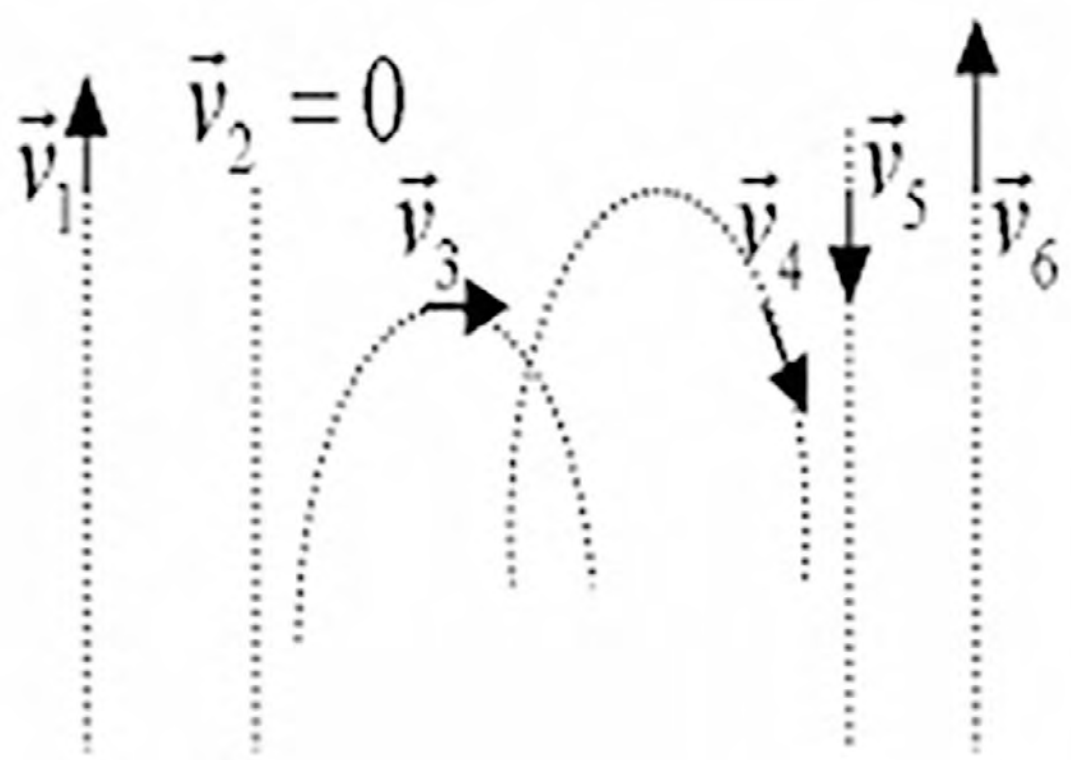

Fonte: Peduzzi (2005, p. 57). 
A análise das respostas relativas à primeira questão pode ser visualizada na Figura 2. Primeiramente, o que se pode observar é que praticamente não existem diferenças entre as respostas obtidas em 2008 e 2016, uma vez que a grande maioria (mais de 70\%) respondeu que as forças que agiam sobre as massas eram diferentes, resposta que leva em consideração a CA que relaciona diretamente velocidade com força $\left(\mathbf{F} \sim \mathbf{k v}^{1}\right)$, desprezando completamente a segunda lei de Newton: $\mathbf{F}=\mathbf{m a}^{2}$.

Figura 2 - Respostas para a primeira questão
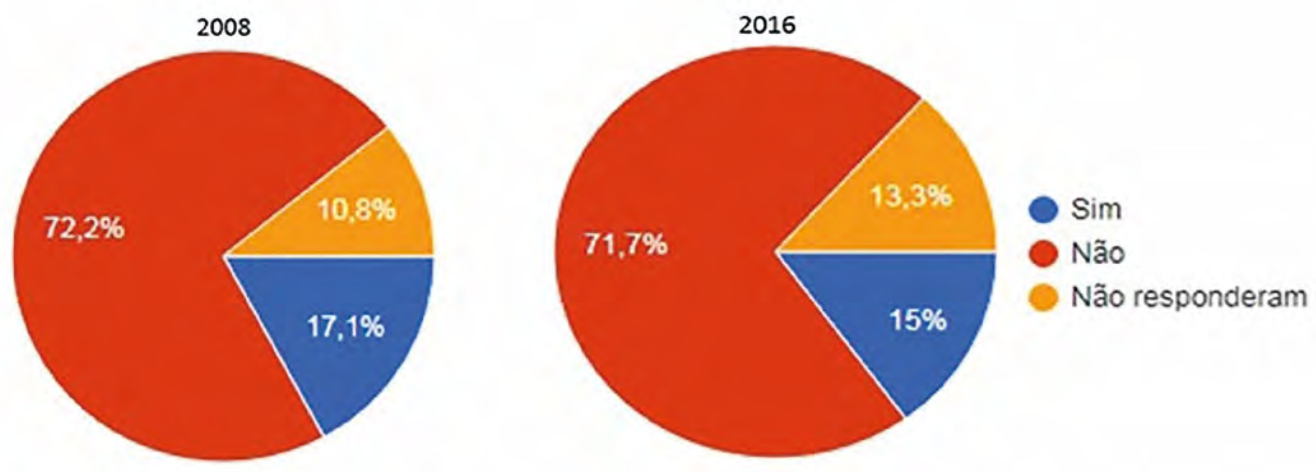

Fonte: dados da pesquisa.

Nota: a alternativa correta é "sim".

$\mathrm{Na}$ segunda questão, afirmava-se que, para manter um carrinho em movimento retilíneo, com velocidade constante sobre uma mesa horizontal, era preciso puxá-lo com força constante, paralela à superfície da mesa, indicando que a força de atrito atuante sobre o carrinho seria igual, em módulo, à força aplicada. $\mathrm{Na}$ questão (Figura 3), apenas $14,6 \%$ dos alunos indicaram a alternativa correta em 2008 e 20\%, em 2016. Novamente, fica evidente a presença da CA F $\mathbf{k v}$, tendo em vista que mais de $44 \%$ dos alunos, nas diferentes épocas, indicaram a alternativa em que deveria se ter uma força resultante para que houvesse movimento. 
Figura 3 - Respostas para a segunda questão
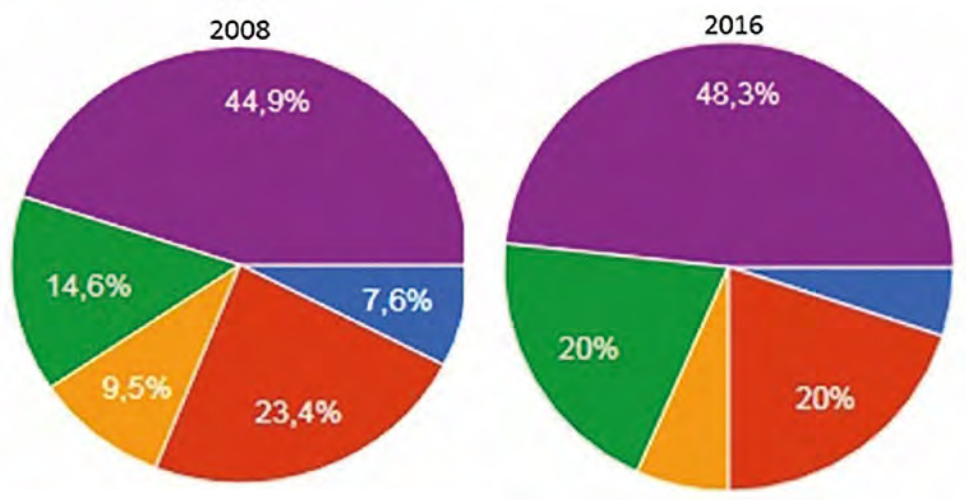

- Apenas a força atua no carrinho;

Apenas a força e o peso estão atuando no carrinho;

- A força de reação à força também está atuando no carrinho:

- A força de atrito, que está atuando no carrinho, é igual, em módulo, à força aplicada;

A força de atrito, que está atuando no carrinho, é menor, em módulo, do que a força aplicada.

Fonte: dados da pesquisa.

Nota: a resposta correta é "A força de atrito que está atuando no carrinho é igual, em módulo, à força aplicada".

Para a questão 3 (Figura 4), primeiramente, indicava-se que, para um carrinho de massa $\mathbf{m}$ adquirir certa aceleração de módulo a, era necessário que a força resultante tivesse módulo f. Aos estudantes foi perguntado: "qual seria o módulo da força resultante para um carrinho de massa $2 \mathbf{m}$ adquirir uma aceleração de módulo 3a?" . Nessa questão, era necessário apenas aplicar a equação $\mathbf{F}=\mathbf{m a}$, sendo que a maioria dos alunos indicaram a resposta correta (67,7\% e 63,3\%). Considera-se o alto índice de acertos em função da possibilidade de solução da questão por meio de cálculos matemáticos, sem a aplicação de outros conceitos além da segunda lei de Newton. Observa-se a controvérsia presente, pois em questões anteriores, a maioria dos estudantes usou a CA $\mathbf{F} \sim \mathbf{k v}$ para responder questões conceituais e, nessa questão específica, fizeram uso correto da segunda lei de Newton.

Figura 4 - Respostas para a terceira questão
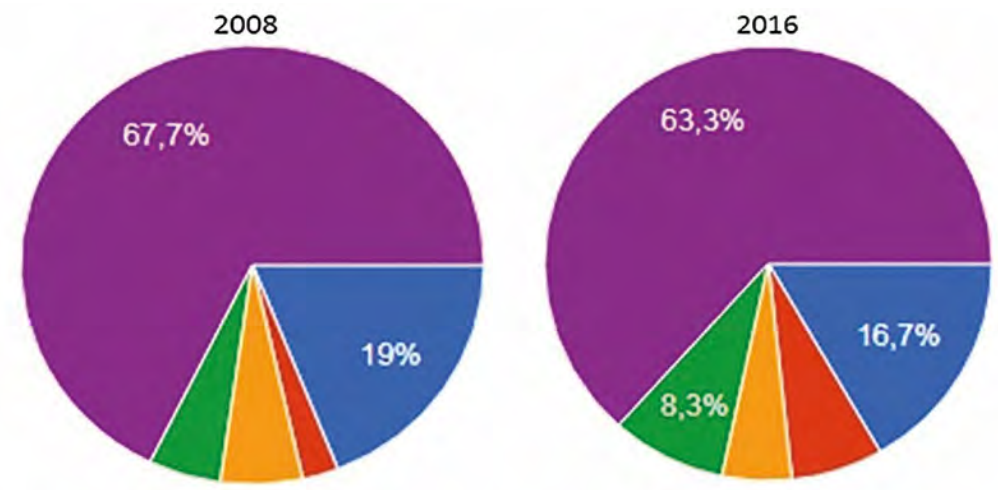

$1,5 \mathrm{~F}$;

$2 \mathrm{~F}$;

$3 \mathrm{~F}$;

$5 \mathrm{~F}$;

$6 F$.

Fonte: dados da pesquisa.

Nota: a alternativa 6F é a correta. 
Na questão quatro, tratava-se do caso de uma pedra que jogada verticalmente para cima, perguntando: "qual seria a sua aceleração no ponto de máxima altitude da trajetória, onde a velocidade é zero?". Nessa questão, mais de $40 \%$ dos alunos, tanto em 2008 quanto em 2016, optaram pela alternativa em que a aceleração inverte o seu sentido, sugerindo que, para se ter velocidade, deve haver aceleração no mesmo sentido, alternativa que evidencia, da mesma forma que em outras questões, o uso da relação F kv. Nessa questão, apenas 12,7\%, em 2008, e 10\%, em 2016, indicaram a opção correta (Figura 5).

$\mathrm{Na}$ quinta e última questão, tratava-se sobre a força resultante que age sobre uma pequena esfera, que cai verticalmente, no interior de um líquido homogêneo, em repouso, que se torna zero a partir de determinado instante. Perguntava-se qual seria, daquele instante em diante, o movimento da esfera. Apenas $24,1 \%$ dos alunos, em 2008, e 13,3\%, em 2016, indicaram que a alternativa correta seria aquela que indicava que a esfera se moveria com velocidade constante para baixo. Nessa questão, a alternativa mais indicada, com $50,6 \%$ para 2008 e 56,7\% para 2016 , afirmava que a esfera permaneceria em repouso, evidenciando novamente o uso da relação F $\mathbf{k v}$ (Figura 6).

Figura 5 - Respostas para a quarta questão
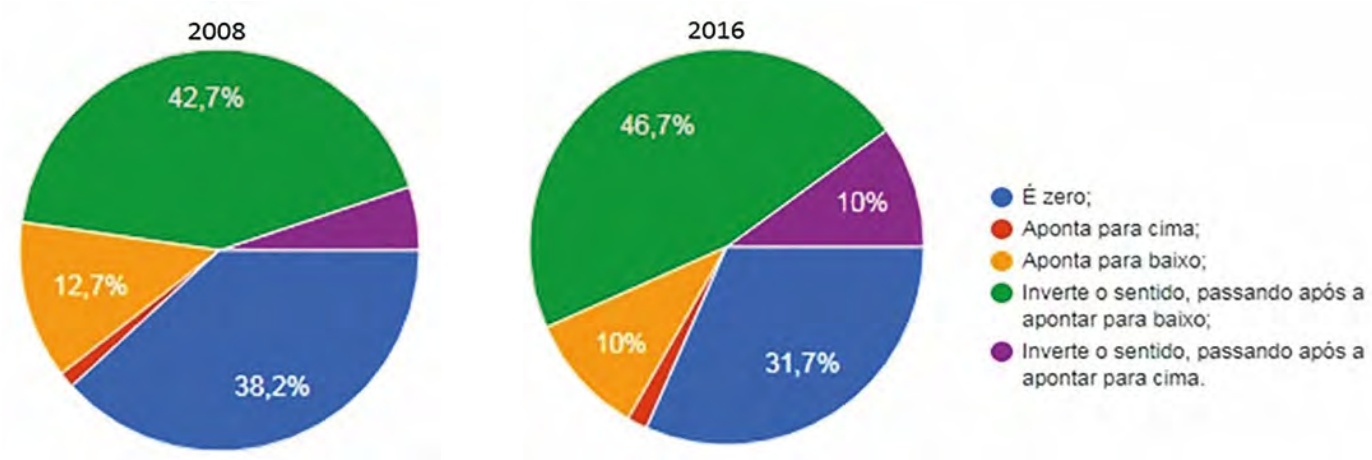

Fonte: dados da pesquisa.

Nota: a alternativa correta é "Aponta para baixo".

Em todas as questões apresentadas fica evidente a presença de CAs na maioria das respostas dos alunos, tanto para o grupo de 2008 como para o grupo de 2016, sendo que os resultados são semelhantes em números, com algumas pequenas variações estatísticas. A forte presença da $\mathrm{CA}$ relativa à relação $\mathbf{F} \sim \mathbf{k v}$ em grande parte dos alunos e nas diferentes épocas deixa evidência de que, na verdade, pouco tem se feito na prática para mudar esse quadro. 
Figura 6 - Respostas para a quinta questão
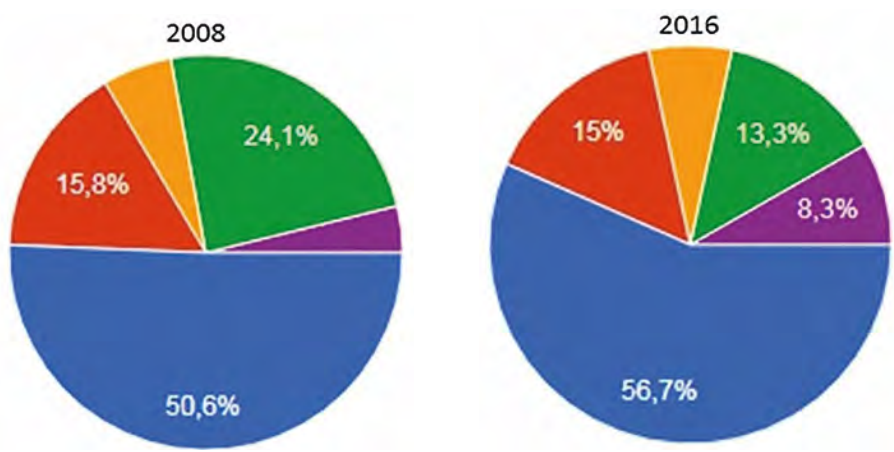

Permanece em repouso em relação ao liquido;

É acelerada de baixo para cima; É acelerada de cima para baixo; Move-se com velocidade constante para baixo;

Move-se com velocidade constante para cima.

Fonte: elaboração dos autores.

Nota: a alternativa correta é "Move-se com velocidade constante para baixo".

Esses resultados permitiram a realização de análises que, em diálogo com outras pesquisas, apresentaram algumas importantes reflexões para o processo de ensino e aprendizagem dos conceitos de física básica que abordaremos na sequência.

Um primeiro aspecto relevante, embora não novo, foi a constatação de que as concepções alternativas dos estudantes investigados são as mesmas dos estudantes de qualquer parte do mundo, daqueles investigados tanto por Axt (1986) quanto por Viennot (1979), fato já relatado exaustivamente na vasta literatura da área. Em outras palavras, as concepções alternativas - CAs - são atemporais e independentes de região.

De modo geral, com os resultados obtidos na aplicação dos questionários, pode-se depreender que, mesmo se tratando apenas da necessidade de resolver a equação e conhecer o conceito de força, constatou-se um número muito elevado de erros, pois grande parte dos estudantes ignorou aspectos relativos à aceleração e à força. Assim, fica evidente que os estudantes, em grande parte, simplesmente, não compreendem questões envolvendo atrito ou ignoram esse aspecto na leitura do enunciado.

Observa-se, também, por meio das respostas ao questionário, que os estudantes aplicam a equação $\mathrm{F}=$ ma na resolução de problemas numéricos, porém usam amplamente a relação $\mathbf{F} \sim \mathbf{k v}$ para a solução de questões conceituais, o que parece sugerir que a eficácia do ensino convencional não vai além de desenvolver a capacidade de aplicar fórmulas. Esse aspecto presente nas diferentes épocas (e em mesmo grau) torna evidente o fracasso em solucionar e/ou erradicar essas CAs presentes nos alunos. Considerando os conceitos abordados sobre aprendizagem significativa, fica clara uma aprendizagem mecânica. 
Todos os resultados deste estudo vão ao encontro das ideias de Peduzzi (2005). $\mathrm{O}$ autor afirma que o indivíduo, como já tem uma explicação própria sobre determinado fenômeno, frequentemente, não aceita bem a visão da ciência. Pode, inclusive, obter a solução correta de problemas que exijam a aplicação direta de equações, demonstrando uma aparente compreensão do conteúdo, no entanto, quando se depara com questões envolvendo situações-problemas que envolvem aspectos conceituais, responde usando o seu esquema conceitual alternativo.

Estudiosos defendem a ideia de que, para que haja uma mudança significativa no ensino e na aprendizagem de física, o estudante deve verificar que existem situações que não se explicam com seu modelo conceitual. Um conceito novo deve ser bem compreendido pelo estudante, ou seja, ele deve saber onde, para quê e como aplicar esse conhecimento. Dessa forma, pensar na possibilidade de se usar as CAs como subsunçores, nos quais novos conhecimentos sejam construídos pelos alunos, leva-nos a inferir que essa poderá ser uma alternativa para a mudança gradual deste quadro problemático no ensino de conceitos básicos de física. Porém, o modo para promover essa mudança deverá ser objeto de novas pesquisas.

\section{Considerações finais}

Considerando esses resultados, percebe-se que o professor, certamente, deve enfrentar grandes dificuldades em proporcionar uma situação em que os alunos possam mudar as suas ideias intuitivas, isso porque, como já indicado em pesquisa anterior (KRAUSE; SANTOS; SANDRI, 2012), os próprios professores ainda carregam consigo concepções alternativas bem enraizadas. De outro modo, essas CAs apresentadas pelos professores necessitam ser consideradas durante a formação profissional dos docentes da área de ciências naturais, pois são transferidas para seus alunos.

Nesse sentido, a formação continuada dos professores, seja por meio de cursos de curta duração (cursos de extensão ou especialização) ou de cursos de pós-graduação stricto sensu (mestrado e/ou doutorado), deve ser objeto de políticas públicas. Para que haja uma mudança significativa no ensino e na aprendizagem, principalmente de Física, o estudante deve mudar o seu modelo conceitual, o que só vai ocorrer se os professores estiverem devidamente preparados para o enfrentamento adequado dessa situação. 


\section{Notas}

1 Nesta equação $\mathbf{F}$ é a força, $\mathbf{v}$ a velocidade e $\mathbf{k}$ uma constante de proporcionalidade.

2 Equação referente a $2^{\text {a }}$ lei de Newton, onde $\mathbf{F}$ é a força, $\mathbf{m}$ a massa e a aceleração.

\section{Referências}

AUSUBEL, David P. Aquisição e retenção de conhecimentos: uma perspectiva cognitiva. Traduzido por Lígia Teopisto. Lisboa: Plátano, 2003.

AXT, Rolando. Conceitos intuitivos em questões objetivas aplicadas no concurso vestibular unificado da Universidade Federal do Rio Grande do Sul. Ciência e Cultura, Porto Alegre, v. 38, n. 3, p. 444-452, 1986.

CARVALHO, Julio Cesar Q.; COUTO, Sheila G.; BOSSOLAN, Nelma R. S. Algumas concepções de alunos do ensino médio a respeito das proteínas. Ciência \& Educação, Bauru, v. 18, n. 4, p. 897-912, 2012.

CAVELLUCCI, Lia Cristina B. Estilos de aprendizagem: em busca das diferenças individuais. 2010. Disponível em: <http://www.iar.unicamp.br/disciplinas/am540_2003/lia/estilos_de_aprendizagem.pdf $>$. Acesso em: 10 jan. 2014.

CORRÊA, André L. et al. História e Filosofia da Biologia como ferramenta no ensino de evolução na formação inicial de professores de Biologia. Filosofia e História da Biologia, São Paulo, v. 5, n. 2, p. 217-237, 2010.

DELIZOICOV, Demétrio; ANGOTTI, José A.; PERNAMBUCO, Marta M. Ensino de ciências: fundamentos e métodos. São Paulo: Cortez, 2002.

DRIVER, Rosalind. Psicología cognitiva e esquemas conceptuales de losalumnos. Enseñanza de las Ciencias, Barcelona, v. 1, n. 4, p. 3-15, 1986.

FARIA, Wilson de. Aprendizagem e planejamento de ensino. São Paulo: Ática, 1989.

FIGUEIRA, Angela C. M.; ROCHA, João B. T. Investigando as concepções dos estudantes do ensino fundamental ao superior sobre ácidos e bases. Revista Ciências \& Ideias, Rio de Janeiro, v. 3 , n. 1, p. 1-21, 2011.

GIORDAN, André; DE VECCHI, Gérad. As origens do saber: das concepções dos aprendentes aos conceitos científicos. 2. ed. Porto Alegre: Artmed, 1996.

HARRES, João B. S. Um teste para detectar concepções alternativas sobre tópicos introdutórios de ótica geométrica. Caderno Catarinense de Ensino de Física, Florianópolis, v. 10, n. 3, p. 220-234, dez. 1993.

KÖHNLEIN, Janete F. K. Um estudo a respeito das concepções alternativas sobre calor e temperatura. 2013. Disponível em: <https://repositorio.ufsc.br/handle/123456789/105335>. Acesso em: 12 jan. 2018. 
KRAUSE, João C.; SANTOS, Antonio V.; SANDRI, Helena. Concepções alternativas sobre Física Básica dos professores da rede pública da região de Santo Ângelo-RS. In: SIMPÓSIO DE ENSINO DE FÍSICA E MATEMÁTICA, 2, 2012, Santa Maria, RS. Anais... Santa Maria: Unifra, 2012. p. 35-46.

LOUZADA, Alexandre N.; ELIA, Marcos da F.; SAMPAIO, Fábio F. Concepções alternativas dos estudantes sobre conceitos térmicos: um estudo de avaliação diagnóstica e formativa. Revista Brasileira de Ensino de Física, São Paulo, v. 37, n. 1, p. 1508-1/9, 2015.

MOREIRA, Marco A. O que é afinal aprendizagem significativa? Aula Inaugural do Programa de Pós-Graduação em Ensino de Ciências Naturais, Instituto de Física, UFMT, Cuiabá, MT, 23 de abril de 2010. Disponível em: <http://moreira.if.ufrgs.br/oqueeafinal.pdf>. Acesso em: 12 jan. 2018.

MOREIRA, Marco A.; MASINI, Elcie F. S. Aprendizagem significativa: a teoria de David Ausubel. 2. ed. São Paulo: Centauro, 2006.

SCHEID, Neusa M. J. A contribuição da história da Biologia na formação inicial de professores de Ciências Biológicas. 2006. Tese (Doutorado em Educação Científica e Tecnológica) - Universidade Federal de Santa Catarina, Florianópolis, 2006.

SILVA, Alcina Maria T. B. Concepções alternativas dos conhecimentos científicos: elementos para a determinação de sua gênese. 2004. Disponível em: <http://www.cienciamao.usp.br/dados/epef/_ concepcoesalternativasdo.trabalho.pdf>. Acesso em: 12 jan. 2018.

SILVA, Elifas L. da. Aspectos motivacionais em operação nas aulas de Física do ensino médio, nas escolas estaduais de São Paulo. Dissertação (Mestrado em Educação) - Instituto de Física, Universidade de São Paulo, São Paulo, 2004.

SILVA, Márcia G. L.; NÚÑEZ, Isauro B. Concepções alternativas dos estudantes. Natal: SEDIS/ UFRN, 2007.

SILVEIRA, Mariana L. Dificuldades de aprendizagem e concepções alternativas em Biologia: a visão de professores em formação sobre o conteúdo de citologia. 2013. Dissertação (Mestrado Profissional em Ensino de Ciências Naturais e Matemática) - Programa de Pós-Graduação em Ensino de Ciências Naturais e Matemática, Universidade Federal do Rio Grande do Norte, Natal, 2013.

PEDUZZI, Sonia S. Concepções alternativas em mecânica. In: PIETROCOLA, Mauricio (Org.). Ensino de Física: conteúdo, metodologia e epistemologia em uma concepção integradora. Florianópolis: Editora da UFSC, 2005. p. 53-75.

VIENNOT, Laurence. Spontaneous reasoning in elementary dynamicsç. European Journal of Science Education, Abingdon, UK, v. 1, n. 2, p. 205-221, 1979. 